CIUDAD Y TERRITORIO

ESTUDIOS TERRITORIALES

ISSN(P): 2697-231X; ISSN(E): 2697-2328

Vol. LIII, N.ำ Monográfico 2021

Págs. 43-60

https://doi.org/10.37230/CyTET.2021.M21.03

CC BY-NC-ND

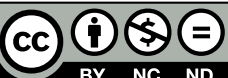

\title{
El ocaso de un modelo de vivienda de difícil reemplazo
}

\author{
Jesús LEAL-MALDONADO ${ }^{(1)}$ \\ Almudena Martínez-del OLmo ${ }^{(2)}$
}

${ }^{(1)}$ Fundación ESNE. Profesor Sociología. Universidad Complutense de Madrid

(2) Universidad Nebrija

Resumen: Se trata de explicar el proceso de cambio del modelo residencial español concentrado durante más de medio siglo en un desarrollo de la propiedad, con una mínima inversión pública directa que trae como resultado la escasa dimensión actual del parque de vivienda social que impide alojar adecuadamente a los segmentos de población más afectados por la elevación de los alquileres en las grandes ciudades que no tienen recursos para acceder al mercado, como son los hogares de inmigrantes, los de rentas bajas y parte de los de nueva formación. Los elevados recortes experimentados en esa inversión tras la crisis financiera y la orientación de las medidas hacia la mejora de los arrendadores, ha agudizado la crisis. Para su solución se hace necesaria una revisión de los medios utilizados hasta ahora y que se replantee un presupuesto más adecuado a las necesidades residenciales, con objetivos durables en el tiempo que se centren en posibilitar a todos los ciudadanos el ejercicio del derecho que tienen a una vivienda adecuada y digna.

Palabras clave: Modelo residencial; Alquiler de vivienda; Políticas de vivienda; Acceso a la vivienda.

\section{The decline of a residential model difficult to be replaced}

Abstract: The current housing crisis is expressed in the difficulty in accessing to a home for new households and for those with lower incomes, who couldn't become homeowners in recent years from the inability to afford it and the disproportionate increase in rents in large Spanish cities. This crisis has to do with the failure of policies that for more than half of a century have been promoting access in property and intervening with objectives and means that distorted the main purpose that public action must have, such as facilitating the disposition of a home to those households that cannot access the free market. The

Recibido: 08.07.2020; Revisado: 03.11.2020.

Correo electrónico: leal.je@gmail.com; N. ORCID: https://orcid.org/0000-0002-0366-9258

Correo electrónico: amartinezol@nebrija.es; N. ${ }^{\circ}$ ORCID: https://orcid.org/0000-0001-9865-9257

Los autores agradecen los comentarios y sugerencias realizados por los evaluadores anónimos, que han contribuido a mejorar y enriquecer el manuscrito original. 
conclusion is that a deep change is needed, involving a replacement of the means used up to now, and that more appropriate a budget to residential needs should be reconsidered, with long-term objectives that focus on enabling all citizens to exercise of the right they have to an adequate and decent home.

Key words: Residential model; Rental housing; Housing policies; Access to housing.

\section{Introducción ${ }^{1}$}

e nuevo, como un acontecimiento recurrente, la vivienda ha vuelto a convertirse en uno de los principales problemas sociales percibidos por los españoles. Esta renovada consideración viene inducida por las dificultades de acceso a este bien necesario que debiera estar garantizado por los poderes públicos, según el articulo 47 de la Constitución Española y que, a pesar de los años transcurridos desde su aprobación, todavía sigue huérfano de una ley que lo convierta en un derecho positivo y aplicable, tal como se ha producido en otros países (LÓPEZ RAMÓN, 2010; VAQUER, 2011). Este retraso lleva a preguntarse por esa dificultad de modificar el nuevo modelo de provisión de viviendas en España ligado al contenido real de las políticas de vivienda.

En este artículo se establece la situación actual del modelo residencial español como el final de una etapa, por la inadaptación a las necesidades de una parte de los hogares, especialmente en el caso de las grandes ciudades donde se vuelve a dar un distanciamiento con las zonas rurales (MódENES, 2009). Su renovación se hace muy difícil debido a la obsolescencia actual de gran parte las medidas de la política de vivienda, incapaces de garantizar un alojamiento adecuado a un segmento importante de estos hogares (HERNÁNDEZ, 2013).

En ese sentido se parte de dos hipótesis principales. La primera es que la crisis actual de alojamiento es la expresión de un fin de ciclo que induce un cambio profundo en lo que podemos denominar el sistema residencial (GARcía PÉREZ \& JANOSCHKA, 2016; PAREJA \& SÁNCHEZ, 2012; MóDENES \& LÓPEZ-COLÁS, 2012).

La segunda hipótesis es que la escasa incidencia actual de las medidas que venían sucediéndose en la política de vivienda requieren un replanteamiento que suponga el desarrollo de un modelo alternativo más adecuado a las nuevas necesidades de todos los hogares, especialmente de los que disponen de menos ingresos

\footnotetext{
1 Esta investigación se desarrolla en el marco del proyecto de investigación del Plan Nacional I+D+i: del Ministerio de Ciencia e Investigación con el título "Influencia de los
}

en las grandes ciudades. Este replanteamiento implicaría un incremento notable del parque de viviendas sociales en alquiler, pero el elevado coste que supone plantea serias incertidumbres sobre sus posibilidades de realización en un contexto económico como el actual, debido a que el sistema está escasamente dotado de recursos para la inversión directa en viviendas sociales que arrastran un enorme déficit. El débil intento de reversión de este sistema durante los últimos años ante su insostenibilidad, ha incidido sobre todo en una extensión del régimen de alquiler cuyo reciente encarecimiento supone una dificultad añadida para solucionar las necesidades actuales más acuciantes de vivienda de los hogares de gran parte de los jóvenes recién emancipados, de los inmigrantes y de los de rentas bajas que se ven obligados a un esfuerzo excesivo para poder alojarse.

Para conseguir este objetivo, se parte en primer lugar de una exposición de la metodología empleada, seguida de la profundización en el concepto de vivienda y del comportamiento residencial. A continuación, se establece la explicación del cambio en el sistema de provisión de viviendas en relación con el acceso de los hogares más desfavorecidos, para lo cual se juzga importante el análisis de las tendencias y de los instrumentos que han guiado la política de vivienda en el último medio siglo hasta llegar a la situación actual. Esta situación exige una revisión del modo de intervención pública para poder garantizar el acceso a todos a una vivienda adecuada, para lo que se propone la extensión del exiguo parque de vivienda social existente en la actualidad que suponga acortar la distancia que tiene con la media europea.

\section{Metodología}

Para conseguir esos objetivos nos encontramos con los condicionantes de la información disponible que supone la escasez de datos espacialmente desagregados, en concreto, de los que dan cuenta de los comportamientos

cambios en los regímenes de producción y acceso a la vivienda sobre la reestructuración social de las grandes ciudades españolas" CSO2017-83968-R. 
residenciales y de las condiciones de las viviendas en relación con las necesidades actuales de alojamiento en las grandes ciudades, que es donde se concentran los problemas más acuciantes.

La información sobre la vivienda se centra sobre todo en una serie de aspectos que no permiten tener una visión completa. Frecuentemente se evalúan los efectos de la intervención pública en relación con el número de viviendas construidas, pero no se analizan los efectos sobre el conjunto de infraviviendas, sobre el hacinamiento, sobre los tiempos de desplazamiento al trabajo o a los servicios elementales, ni sobre la carga económica que implica a los hogares, especialmente a los más desfavorecidos, en relación con los nuevos estándares que habría que considerar en la sociedad actual, lo que mediría de forma más adecuada los efectos de las políticas y del mercado.

Los análisis se centran con frecuencia aspectos fácilmente cuantificables desde la perspectiva numérica de su producción, y de su economía, pero son escasos en lo que KEMENY (1992) denomina el comportamiento residencial, como no sea el de sus características demográficas y económicas más esenciales, lo que dificulta la evaluación de las políticas que parecen guiarse preferentemente por el volumen de los datos sobre la construcción, por sus aspectos físicos, y por las formas de apropiación y del coste que suponen. Pero sabemos poco de quien habita cada tipo de vivienda social o de las que han sido objeto de una intervención pública como las Viviendas de Protección Oficial (VPO) o las propias viviendas públicas, algo que podría medir la efectividad real de las políticas aplicadas.

En este trabajo tenemos que limitarnos a la evaluación del sistema de vivienda a partir de los datos disponibles de las políticas estatales y a partir de los planes de vivienda y de su dotación, sin poder verificar claramente sus efectos directos. Para ello se han analizado las fuentes principales de información sobre la vivienda publicadas por el Instituto Nacional de Estadística: censos, encuestas nacionales, y estadísticas registrales, a los que hay que añadir los datos sobre la dinámica de la vivienda publicados por el Ministerio de Transportes, Movilidad y Agenda Urbana. En el caso de los precios, se ha consultado la información del Banco de España y también la página de Idealista.com.
En el tratamiento de estos datos se ha intentado, siempre que haya sido posible, la formación de series que nos permitan percibir en su evolución las tendencias del sistema que corroborarían las hipótesis planteadas. El planteamiento generalista que se hace ha aconsejado un tratamiento elemental de la información cuantitativa recogida, completada con el recurso a los resultados de investigaciones publicadas de diversos autores.

\section{La vivienda}

La vivienda es un bien necesario, cuya garantía de acceso es objeto de un derecho establecido como tal por el artículo 47 de la Constitución española y por las Naciones Unidas ${ }^{2}$, que da lugar a un derecho positivo en muchos países. Su sentido va más allá de la pura utilidad de dotar de un cobijo a las personas que la habitan, teniendo múltiples funciones que han evolucionado con el tiempo en las sociedades occidentales, estando acompañado su uso de significados sociales que van más allá de la descripción física de sus espacios tal como plantean algunos autores (CoRTES, 1995; SEgaUd. 2008) En ese sentido las dificultades para acceder a una vivienda adecuada (que la Constitución Española califica como digna), más allá de esa posibilidad de alojarse, afecta a los procesos de socialización, al sistema de relaciones sociales y a la distribución de los recursos de capital entre los hogares.

La consideración histórica de la vivienda nos lleva a la constatación de una evolución en su funcionalidad. Si analizamos los cambios experimentados en sus usos, nos encontramos que secularmente la vivienda ha contenido en múltiples situaciones y más precisamente en el medio rural, una función productiva, como espacio de actividad tanto ganadera, como de almacenaje y de desarrollo de actividad directa. Estas funciones como espacio de trabajo se han transmitido también a la vivienda urbana y se están viendo aumentadas actualmente con el teletrabajo, a partir del uso de las nuevas tecnologías de la información, como se ha constatado en la crisis producida por el Covid 19, presentándose como un proceso creciente con repercusiones en la elección residencial que puede cambiar de manera profunda la forma urbana de nuestras ciudades.

\footnotetext{
${ }^{2}$ Observación General n. ${ }^{\circ} 4$ del Comité de Derechos Económicos, Sociales y Culturales de las Naciones Unidas.
} 
Si examinamos la distribución de una vivienda de hace un siglo (HAMMAD, 2006) y la comparamos con la actual, percibimos las considerables diferencias que ha supuesto ese cambio en sus funciones, acorde con las nuevas exigencias sociales, como sucede con las actividades de aseo y con la elaboración de alimentos, pero también con la ampliación de un espacio dedicado al ocio del que carecía anteriormente en gran parte de ellas. La penetración de la radio, de la televisión, y de las diversas aplicaciones de internet, implican también un espacio añadido cuya disposición llega a configurarse como una necesidad.

Las funciones tradicionales como los espacios de estar, de aseo o de reposo experimentan también nuevas visiones. Con frecuencia se califica a la vivienda según el número de dormitorios, o de espacios de aseo, con una tendencia a su incremento en aquellas de nuevo diseño. Paralelamente la cocina, en la vivienda urbana, pasa a incluirse en los lugares más representativos de la casa, al mismo tiempo que se reduce el espacio de su almacenaje en las despensas que existían junto a ella en la antigua distribución de la vivienda urbana.

Todo ese cambio justifica el incremento progresivo del tamaño de la vivienda cuya superficie sigue creciendo a pesar de la reducción del hogar, habiendo alcanzado una media de 101 m² $^{2}$ en 2019 para España, aunque esta superficie es menor en las grandes ciudades siendo de $90 \mathrm{~m}^{2}$ para la Comunidad de Madrid y $91 \mathrm{~m}^{2}$ para la provincia de Barcelona, esto es debido a que las nuevas viviendas están contribuyendo al aumento medio de su tamaño en el conjunto del parque ${ }^{3}$. La vivienda también es un espacio de socialización, con especial consideración de los miembros que componen el hogar y su forma de relacionarse, aunque los significados y usos cambian en función de la edad y de la condición de sus habitantes. Desde esa perspectiva (PEZEU-MASSABUAU, 2013) plantea la dificultad de la socialización de sus residentes, cuando se vive en una infravivienda.

La consideración de estas funciones ayuda a dimensionar los efectos de la reclusión producida por el Covid 19, cuando la inadecuación de un espacio residencial obligaba a un uso más intensivo del espacio público circundante, con la consecuencia de una correlación entre la

\footnotetext{
${ }^{3}$ Resulta significativo que sea Cuenca la provincia española que tiene la media más elevada del tamaño de sus viviendas: 158 metros cuadrados, según el INE.

${ }^{4}$ Tal como se deduce de los mapas interactivos sobre la
}

proporción de contagios y la precariedad residencial ${ }^{4}$. Ello lleva a la exigencia no solo a una provisión de más viviendas sociales, sino también a la necesidad de adaptación de los espacios residenciales que pasa frecuentemente por procesos de rehabilitación y por la revisión de los estándares que definen las características básicas de una vivienda adecuada y digna.

Más allá del contenido de sus funciones, la vivienda tiene una serie de significados que afectan de forma directa a sus habitantes. RAPPOPORT (1972), SEGAUD (2008) y HAMMAD (2006) dan cuenta de esos significados ligados al carácter más público o privativo de su espacio, a los valores y normas sociales y a la propia calificación de sus habitantes.

Finalmente hay que destacar el hecho de la localización de la vivienda y de su entorno como un elemento importante de calificación social. En las ciudades españolas con elevadas tasas de segregación residencial, el lugar donde se vive afecta directamente a la imagen de la condición social de las personas (MARTINEZ VEIGA, 1999; LEAL \& SORANDO, 2016). Este hecho ha llevado en ciertos países a un cambio de políticas de vivienda que ha pasado de la construcción de barrios enteros de vivienda social a una distribución más mezclada de dichas viviendas que trata de ser más equilibrada en relación con la valoración social de los espacios urbanos.

En consecuencia, cuando se trata de la vivienda se está tratando de un bien complejo que es único en cada uno de sus elementos y en el que cualquiera de sus variaciones o de sus cambios tiene una notable repercusión sobre la vida de las personas que la habitan. En ese sentido la vivienda puede tener un valor económico muy diferente según el lugar en el que se ubique, ya sea un medio rural o urbano y dentro de este según el barrio en el que esté asentada. Ese valor puede depender de factores externos, como las características de su entorno, en términos de dotaciones o de sus posibilidades de acceso a los medios de transporte o el contenido social de un barrio, más allá de la calidad de su entorno, de su funcionalidad o de los materiales con la que se ha construido, hasta el punto de existir una correlación elevada entre las categorías sociales dominantes en un barrio y el precio de la vivienda como ha mostrado RocH (2008). En consecuencia, las expectativas de

situación del virus comparado con los mapas sobre la estructura social de Madrid https://www.comunidad.madrid/ servicios/salud/2019-nuevo-coronavirus\#situacion-epidemiologica-actual Internet 09/10/2020. 
cambio de esas categorías van a dar lugar también a cambios en la valoración económica tal como se presentan en los procesos de segregación, y en la denominada gentrificación (OBERTI \& Preteceille, 2016; Leal \& Sorando, 2016).

Por todo lo expresado hay que tener en cuenta que los comentarios agregados sobre los procesos de las viviendas han de ser tomados con mucho cuidado porque pueden incluir diferencias notables que pongan en entredicho las conclusiones que su análisis pueda determinar. Existen mercados diferenciados de vivienda que al agregar sus valores desvirtúan parcialmente las visiones concretas que pueden darse en cada uno de los barrios de una ciudad. Cuestiones tales como la proporción de viviendas vacantes, pierden el sentido al agregar los espacio rurales y urbanos o las zonas turísticas en las grandes aglomeraciones. Lo mismo puede suceder con la agregación de los precios, del tamaño, de la habitabilidad, del estado físico y de otras características a las que se suele hacer referencia cuando se trata de la vivienda de forma agregada de una localidad, región o país.

\section{El cambio del modelo residencial español y la formación de la crisis de la vivienda urbana}

A lo largo del último medio siglo, las condiciones de acceso a una vivienda adecuada en España ha evolucionado de forma cíclica en su consideración de problema social de considerable importancia, aunque con características diferentes en cada caso. La vivienda se ha convertido en una mercancía cuyas condiciones siguen considerándose con demasiada frecuencia como las de cualquier otro bien sometido a las leyes implacables del mercado, omitiendo que, a diferencia de otros bienes mercantiles, se trata de un bien necesario y único cuya disposición es un derecho.

Especialmente en los últimos 20 años se ha producido una evolución del modelo residencial español en el que tras la enorme explosión de crecimiento de la población y de las viviendas en los primeros años del siglo XXI, que arrastró en su caída a todo el sistema financiero del país (FIG. 1), se produce un cambio estructural que obliga a un replanteamiento de sus consecuencias por los efectos que produce en los grupos sociales, tanto los que se diferencian por su edad (jóvenes, mayores...) como los que dan cuenta de sus características económicas y sociales.

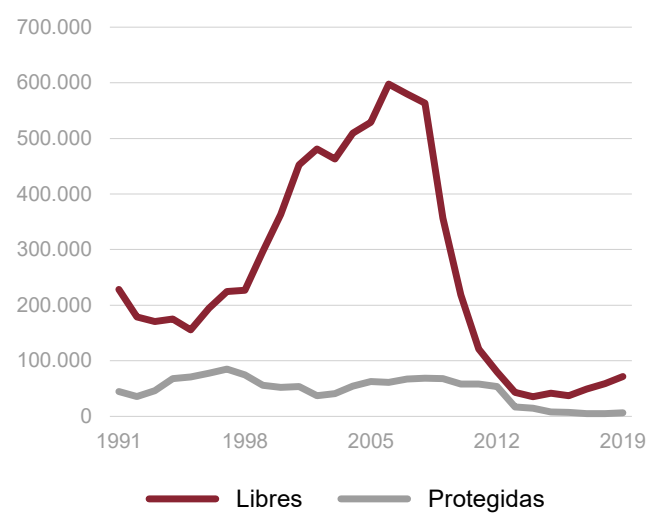

FIG. 1/ Producción de vivienda en España por régimen de protección (1991-2018).

Fuente: MINISTERIO DE TRANSPORTES, MOVILIDAD Y AGENDA URBANA.

La forma actual de la crisis del sistema residencial español viene marcada por la dificultad de los hogares jóvenes y de los más desfavorecidos en procurarse un espacio residencial en el que poder constituir un hogar en el que desarrollar su proyecto vital. Una dificultad que se expresa por indicadores como el de la proporción de la renta dedicada al alquiler o la compra, el espacio medio por habitante, o el compartir con extraños ese espacio residencial. Es una crisis que se muestra con más acritud en las grandes ciudades, especialmente en aquellas en las que se concentran los mayores incrementos de actividad y las mejores oportunidades de trabajo y en las que las rentas y el precio de las viviendas son más distantes de los niveles salariales medios.

Para comprender el sistema de provisión de viviendas español, hay que considerarlo dentro del régimen de bienestar que provee los bienes y servicios en una economía de mercado, con un modelo específico que se diferencia de otros países del centro y norte de Europa y tiene una cierta similitud con los países del sur (ALLEN \& al., 2004; MódENES \& LóPEZ-COLAS, 2014). Se trata de un régimen de bienestar en el que la intervención del Estado en la inversión en servicios sociales es una de las más bajas proporcionalmente, entre los países del Eurogrupo. En consecuencia, con esa escasa inversión pública, es el mercado el que se atribuye la función casi exclusiva de alojamiento. Esta característica se aprecia de forma más explícita en la comparación con otros países europeos en cuestiones tales como la inversión pública en vivienda, la proporción de viviendas sociales y las ayudas directas para el alojamiento de ciertos sectores de población (TRILLA, 2001). Es de considerar 
que en aquellos regímenes de bienestar en los que existe una mayor implicación estatal, suele haber una mayor proporción de vivienda en alquiler (MUÑOZ FERNÁNDEZ \& SANTOS, 2012).

En el régimen de bienestar español existe otro componente, extensible a los países del sur de Europa, que es el de la solidaridad familiar que interviene de forma más intensa en la provisión de los servicios que en otros países en los que se atribuyen en mayor proporción al Estado (Abrahanson, 2005). Pero hay que tener en cuenta que estos países del sur están afectados por un proceso de cambio notable en la concepción de la familia y más en concreto en su exigencia de aportación solidaria (FLAQUER, 2004). La reducción del ámbito familiar a la esfera más inmediata, la disminución de su tamaño, el incremento de la privatización e independencia de sus miembros y la separación espacial que supone el hábitat familiar en las grandes ciudades, llevan a una pérdida de intensidad y relevancia en el papel que se le atribuía en la provisión de servicios y cuidados y en concreto en las ayudas para el acceso a la vivienda, especialmente en las ayudas no monetarias (PAREJA \& SÁNCHEZ, 2012; MARTíNEZ DEL OLMO, 2020).

A pesar de su disminución, la ayuda directa e indirecta de la solidaridad familiar en el acceso a la vivienda de los nuevos hogares, juega todavía un papel importante, especialmente en el acceso a la propiedad, ya que se considera que en la sociedad actual disponer de un patrimonio era un factor de seguridad importante ante las vicisitudes del futuro, al mismo tiempo que se consideraba con frecuencia que el pago del alquiler era una especie de derroche, en el caso de que se pudiera acceder en propiedad. Esa ayuda familiar puede variar considerablemente en su cuantía y su contenido según las categorías sociales y las rentas percibidas.

En este marco del sistema, la crisis del 2008 supuso un impacto notable en esa condición de la vivienda como valor seguro, al producirse una ruptura no esperada en la continuidad de los empleos que influyó directamente en los impagos de las hipotecas contraídas y como consecuencia, en muchos casos, en la pérdida de los ahorros depositados en su adquisición. Este hecho es importante porque termina con el crecimiento de la proporción de propietarios a lo largo de mas de medio siglo, para dar un nuevo impulso al alquiler de viviendas como alternativa residencial (FIG. 2), especialmente en el caso de los hogares con persona de referencia entre 30 y 45 años, cuya proporción de inquilinos pasa del $19 \%$ al 30\% entre 2011 y 2019 (Encuesta de Condiciones de vida).
Este cambio responde a las nuevas condiciones actuales de los que acceden a una vivienda por varios motivos: el primero de ellos era la discontinuidad y precariedad laboral de los nuevos contratos de trabajo, producida en gran parte por la crisis y ratificada por un cambio en la legislación laboral; ligado a ese hecho estaba la inseguridad en el pago de las hipotecas que podían contraerse con la compra de una vivienda, y la mayor movilidad laboral que obligaba a considerar la preferencia por una localización residencial más flexible hasta que se pudiera consolidar el proyecto laboral y el propio proyecto de hogar.

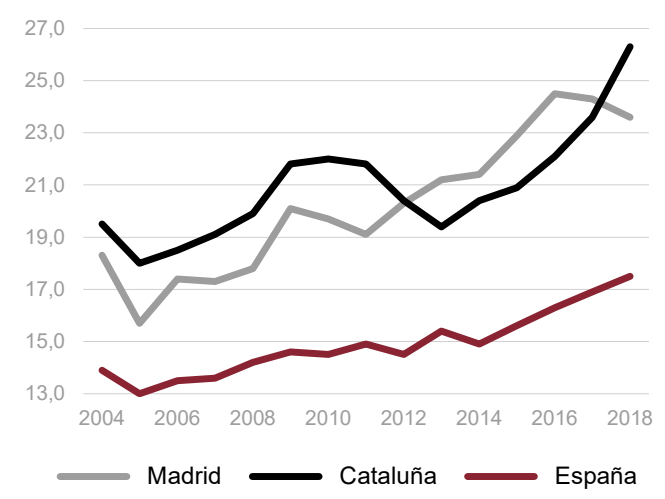

FIG. 2/ Evolución reciente de la proporción de los hogares en régimen de en alquiler en España, Cataluña y Comunidad de Madrid (2004-18).

Fuente: INE Encuesta de Condiciones de Vida.

El aumento de la proporción de la tenencia en alquiler estuvo protagonizado inicialmente, a comienzos del siglo XXI, por los inmigrantes extranjeros para los cuales la adquisición de una vivienda se hacía todavía más difícil, por la mayor precariedad de sus ocupaciones y por la incertidumbre respecto a la localización del nuevo empleo, hasta que el proyecto migratorio y laboral se concretaba. Resulta esclarecedor que en el año 2018 la proporción de hogares en alquiler en España con persona de referencia extranjera, de fuera de la UE, alcanzara el $77,3 \%$, frente al $13 \%$ de los españoles (Encuesta de Condiciones de Vida). En este sentido, el considerable aumento de población extranjera de 5,5 millones que se asienta en Espala en los últimos 20 años, explicaría en parte el incremento del parque de alquileres (FIG. 3), con mayor impacto en aquellas regiones con una proporción de inmigrantes más elevada, como es el caso de las grandes ciudades. 


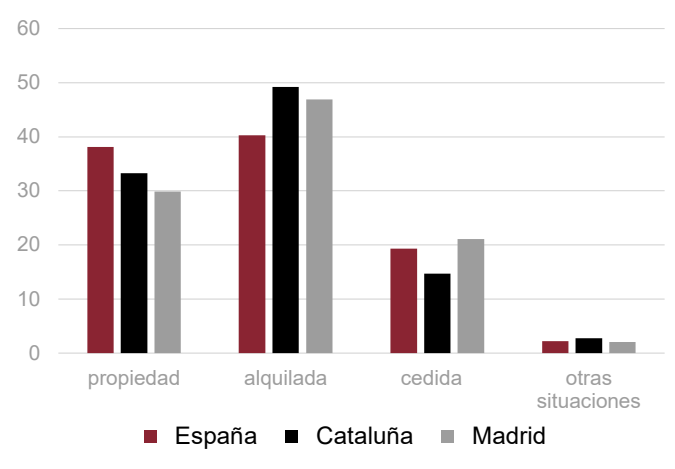

FIG. 3/ Proporción de formas de tenencia de los extranjeros residentes en España, Cataluña y Comunidad de Madrid 2007.

Fuente: INE. Encuesta Nacional de Inmigrantes 2007.

A este aumento del alquiler debido a los inmigrantes, se une a partir de la crisis económica de 2008 la de los nuevos hogares de nativos (ECHAVES, 2017) y la de aquellos que habían sido desahuciados debido a los impagos de las hipotecas adquiridas antes de la crisis, incrementando una demanda que en un cierto tiempo vino favorecida por las políticas de ayuda personal al pago de los alquileres, la denominada renta de emancipación. Pero ese aumento de la demanda coincidió con la saturación de las viviendas más asequibles que fueron disminuyendo su proporción sobre el parque de alquiler (FIG. 4).

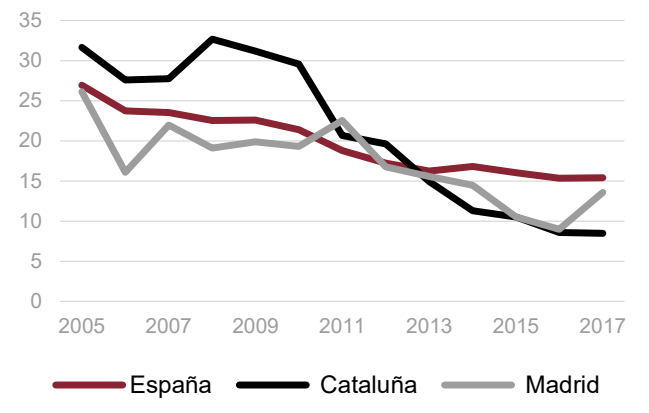

FIG. 4/ Evolución de la proporción de alquileres con precios por debajo del mercado en España, Cataluña y Madrid.

Fuente: INE. Encuesta de Condiciones de Vida.

Las medidas del Plan estatal de Vivienda de 2013 y la nueva ley de arrendamientos urbanos del mismo año trataron de responder a esta situación impulsando medidas que fomentaran el alquiler que ya experimentaba un aumento de demanda. Las facilidades de la nueva ley y la menor subida de los precios de la vivienda en propiedad respecto a los del alquiler (FIG. 5), supusieron un incremento de la rentabilidad de la inversión en este tipo de vivienda que llegó a superar el 5,75\% en 2017 en Madrid y el 5,25 \% en Barcelona en 2016 tal como plantean López Rodríguez \& Mata (2019). La consecuencia fue una canalización de la inversión hacia estas viviendas, con la atracción de fondos de inversión en un sector que había estado dominado casi exclusivamente por un patrimonio familiar, a la vez que se ponía en el mercado una parte del parque vacante (GARCía MonTALVO, 2019; AlVEs \& URTASUN, 2019).

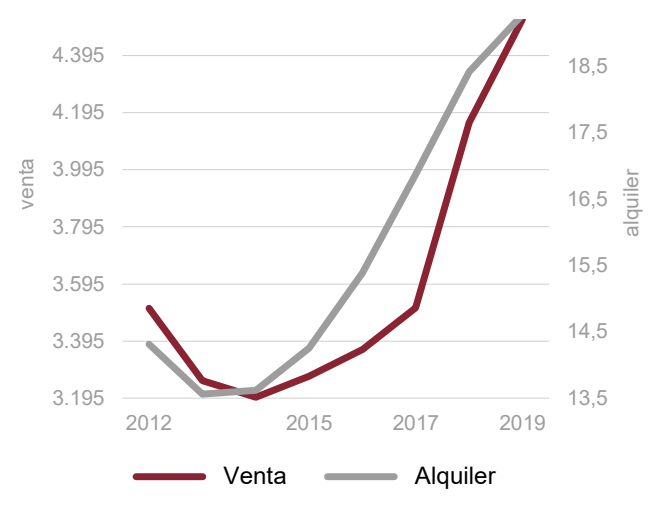

FIG. 5/ Evolución en Madrid de los precios de venta (eje izquierdo) comparado con los precios de alquiler (eje derecho) en $€ / \mathrm{m}^{2}$ (2012-2019).

Fuente: Idealista.com y elaboración propia.

Pero el recurso para aumentar la oferta en alquiler a partir del parque disponible duró poco tiempo, debido a que por una parte la construcción de nuevas viviendas era escasa, en gran parte como consecuencia de la crisis de 2008, que llevó a la bancarrota a una buena cantidad de promotores. Ese retraimiento de la producción de viviendas estaba también influenciado por otros factores como la incógnita del posible crecimiento de los hogares en las grandes ciudades, especialmente en el momento en que el aumento de población del conjunto del país se había congelado, debido al escaso crecimiento vegetativo y a la disminución e incluso a la reversión temporal de los flujos migratorios, especialmente los provenientes de América Latina.

El retraimiento en la nueva edificación venía también impulsado por la existencia de un elevado volumen de viviendas recién construidas sin vender, evaluado en más de 600.000 unidades que daba la imagen de un monumental despilfarro, narrado en diversas publicaciones 
(VINUESA \& PORRAS, 2017), aunque gran parte de esas nuevas viviendas invendidas estaban en localizaciones inapropiadas o en situaciones de difícil gestión por haber sido traspasadas por la bancarrota de sus promotores a los activos de sus acreedores bancarios en una primera fase y posteriormente a la entidad financiera pública (SAREB) que se hizo cargo de ellas en una segunda fase. La lenta ocupación de esas viviendas recién construidas pudo nublar la percepción de una disminución en el conjunto del parque de las viviendas vacías que ya había comenzado antes de la crisis y que se aceleraría en los años siguientes.

El impulso del Plan de Vivienda de 2013 a la tenencia en alquiler no se planteó de dónde vendrían las viviendas que iban a aumentar la oferta que se trataba de impulsar. Los hogares que ya eran propietarios no iban a convertirse en inquilinos a no ser que no pudieran pagar la hipoteca que habían contraído y fueran desahuciados de sus viviendas. La conclusión es que una parte importante del incremento que experimentaron las viviendas en alquiler, especialmente en el caso de las grandes ciudades, provenía de la inclusión en el mercado de las viviendas vacías y de aquellas secundarias que, por su localización cercana a los núcleos urbanos mayores, podían ser alquiladas a los que accedían a una nueva vivienda (LóPEZ RoDRíGUEZ \& MATEA, 2019). Esto explica el rápido descenso de las viviendas no principales (FIG. 6), teniendo que añadir a su aportación las que eran dejadas en herencia o donadas a los familiares por parte de sus progenitores que las desocupaban. De forma más reducida, también se incorporaron temporalmente al alquiler algunas de las viviendas desahuciadas por impago de sus hipotecas

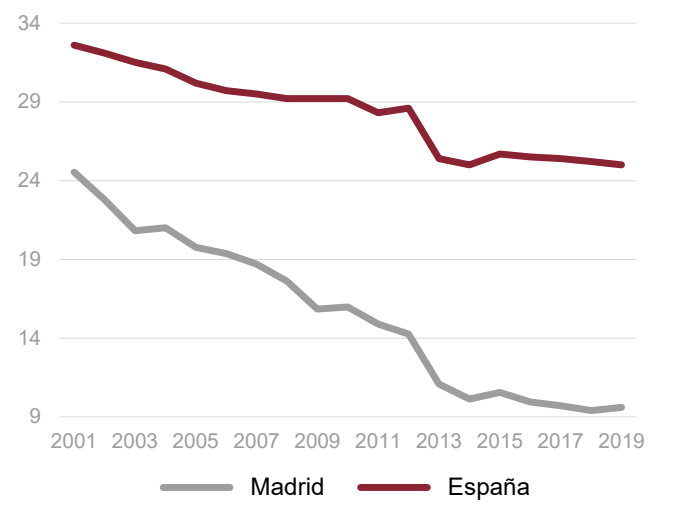

FIG. 6/ Evolución de la proporción de viviendas no principales en Madrid y en España.

Fuente: MINISTERIO DE TRANSPORTES, MOVILIDAD Y AGENDA URBANA. que pasaron a las entidades crediticias y posteriormente al SAREB.

Con ese impulso de su puesta en alquiler, las dimensiones de ese parque de viviendas no principales fueron descendiendo hasta reducirse al mínimo en las grandes ciudades. Hay que tener en cuenta que para que funcione el mercado, necesita una cierta proporción de viviendas que son censadas como vacías y que son las que cubren el periodo desde su puesta en venta o en alquiler hasta la ocupación por un nuevo hogar. El tamaño de ese parque vacío variará según las circunstancias, pero puede llegar a representar hasta un $5 \%$ según autores como (MUTH \& Goodman, 2013). Aunque las estadísticas de la evolución del parque residencial español del Ministerio de Transportes no distinguen entre las secundarias y vacías, es de considerar que su descenso atañe a ambas categorías y que la proporción de vacías puede estar cerca en algunos lugares de ese mínimo necesario.

Al encarecimiento del mercado de alquileres contribuyó también en algunas ciudades el desarrollo de las viviendas de alquiler para cortas estancias, especialmente en las ciudades con gran atracción turística, porque detrajo una cierta proporción de la oferta de alquiler ordinario, especialmente en las zonas centrales de las grandes ciudades.

El incremento de las rentas de los alquileres que siguió a su escasez, detrajo una parte creciente de ingresos disponibles de sus inquilinos, ya que por una parte los salarios no crecían en la misma proporción y por otra parte el acceso a la propiedad continuaba haciéndose difícil, ya que se exigía un $20 \%$ de inversión inicial a la que había que añadir el coste de los impuestos y otros gastos (alrededor del 10\%) del valor de la vivienda que se adquiere, debiendo tener en consideración en muchos casos el coste de la mejora de la vivienda adquirida. El resultado fue un aumento de los pisos compartidos, entre familias o personas de rentas bajas, especialmente entre jóvenes con empleos precarios e inmigrantes.

Otra consecuencia de ese aumento de las rentas de los alquileres fue el mantenimiento de un volumen elevado de los desahucios por el impago de los alquileres (FIG. 7), en contraste con la diminución de los desahucios por impago de las mensualidades de las hipotecas (RoDRíguEZ LóPEZ, 2019).

Ante los problemas que creaban los incrementos de las rentas para un segmento de inquilinos, debidos al Covid 19, una de las primeras medidas del nuevo gobierno, a comienzos del 2020 fue 


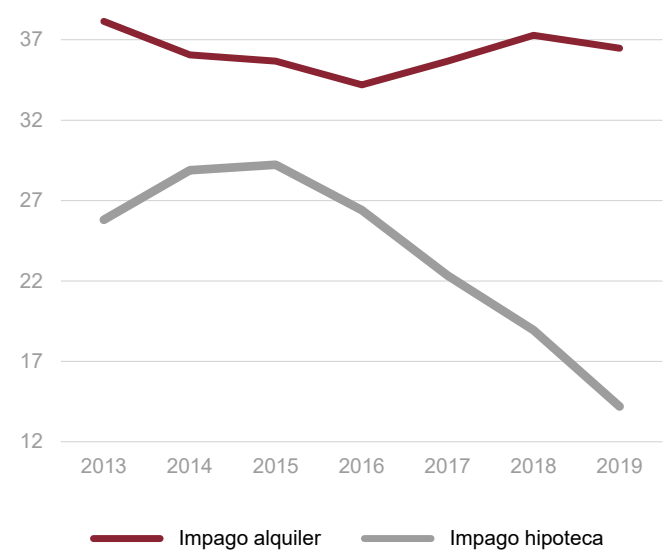

FIG. 7/ Evolución de los lanzamientos por impago de hipotecas y de alquiler en España en miles (20132019).

Fuente: EUROPA PRESS Data: a partir de estadísticas del Consejo General del Poder Judicial.

la promulgación de un decreto que cambiaba el tiempo obligatorio de los nuevos alquileres, restituyéndolo a los 5 años que planteaba la ley de arrendamientos de 1994 y estableciendo poco después, debido al impacto del Covid 19, mayores garantías cuando los impagos se debían a la carencia de recursos de los inquilinos, con una moratoria ${ }^{5}$ de nuevos desahucios hasta Enero de 2021, para el caso de los hogares más vulnerables que permitía el retraso de su pago cuando las circunstancias económicas de los hogares suponían la incapacidad de efectuarlo. Con ello se ha relegado el debate sobre las medidas de limitación espacial y temporal del aumento de los alquileres tal como se practica en otros países ante los elevados valores alcanzados en algunos barrios de las grandes ciudades (Nueva York, Londres, Paris, Berlín).

A la hora de escribir este artículo, resulta todavía imposible evaluar las consecuencias que ha tenido el encierro forzado de esos meses, pero es cierto que la incertidumbre sobre el futuro inmediato de las viviendas de alquiler temporal reducido (turísticas), ha llevado a algunos de sus propietarios a transformarlas en alquileres permanentes, incrementando algo la oferta y contribuyendo a rebajar la tensión del crecimiento de las rentas de los alquileres.

\footnotetext{
${ }^{5}$ A quienes paguen un alquiler / una renta y se encuentren desempleados debido a la crisis del Covid-19, a quienes haya sufrido un ERTE, a quienes hayan visto reducida su jornada por cuidado de niños o personas mayores y a quienes se vean afectados por otras circunstancias que supongan una pérdida sustancial de ingreso, quienes se vean afectados por circunstancias que supongan una pérdida sustancial de ingreso.
}

\section{Las constantes de la política de vivienda}

El rápido cambio producido en la tenencia de los nuevos hogares lleva a replantearse la forma como se viene expresando la política de vivienda en España actualmente. Actuaciones tales como la supresión y restauración de la desgravación por compra de vivienda primaria, el establecimiento de ayudas directas al alquiler para los jóvenes, suprimidas más tarde, y más recientemente la rectificación del acortamiento del límite temporal de los contratos de alquiler de viviendas que había supuesto la ley de 2013, nos dan idea de las diferencias de criterio entre los sucesivos gobiernos para resolver el problema del acceso a la vivienda.

Se trata de una discontinuidad en los criterios de la política de vivienda que tiene también su origen que la carencia de una cultura de vivienda, con la comprensión y evaluación de las medidas públicas de intervención que faciliten las actuaciones continuadas a largo plazo que reorienten el régimen actual de provisión de viviendas. Las investigaciones, las publicaciones, los debates y las conferencias sobre la situación de la vivienda y las políticas residenciales son muy escasas si las contrastamos con las de otros países de nuestro entorno y con el coste y la repercusión de esas políticas. A eso hay que añadir el impacto de una concepción, extensible en parte a los otros países del sur de Europa, de que el compromiso de conseguir un alojamiento adecuado de todos corresponde en gran parte al ámbito familiar a través del mercado, quedando solo para el Estado las situaciones más extremas (residuales) que representan una pequeña proporción (ALLEN \& al., 2004), especialmente si lo comparamos con las políticas de enseñanza y sanidad. Un modelo que es ineficiente ante un aumento de la precariedad y del número de hogares con rentas bajas imposibilitados de facilitar esas ayudas a sus miembros.

Las situaciones de escasos recursos de muchas familias plantean una necesaria implicación del Estado con la provisión de viviendas sociales en alquiler a precios inferiores al mercado y frecuentemente acordes con la capacidad económica de los inquilinos. Este tipo de actuación denominado "residualista" por algunos autores ${ }^{6}$

${ }^{6}$ Se entiende por política residualita aquella que va dirigida a una fracción residual de la población, concebida en este caso como los hogares que reúnen una condición determinada, como sería en este caso los que no pueden acceder al mercado libre de vivienda. 
(ARBACl, 2019), es el núcleo principal de las políticas de vivienda en los regímenes de bienestar liberales de Europa, marcándose una gran distancia con el caso español cuya proporción de estas viviendas sociales es una de las más bajas de los países del Eurogrupo, siendo incapaz de ofertar una alternativa residencial adecuada a la mayoría de los más desfavorecidos y de garantizar, un derecho a la vivienda para todos por la escasez del parque de viviendas sociales disponible.

\subsection{Una escasez endémica de viviendas sociales y de alquileres asequibles}

El resultado de esta crisis se convierte en un fracaso de las políticas de vivienda que tras más de medio siglo de fomentar la propiedad no ha llegado a consolidar ese parque de vivienda social en alquiler que garantice a los hogares de bajos ingresos el acceso generalizado a una vivienda adecuada. Se trata de una situación de difícil salida, ya que supondría incrementar de forma muy sustancial la actual inversión pública en vivienda, en competencia con otros servicios que también han tenido recortes por la crisis económica como la sanidad y la enseñanza. Hay que tener en cuenta que el parque de viviendas sociales necesario para alcanzar en España la media de toda la Unión Europea (GARCíAALMIRAL \& ARENDS, 2012) supondría un aumento en torno a 1,5 millones de estas viviendas sobre las ya existentes ${ }^{7}$ a cuya inversión habría que añadir las que necesitan ser repuestas o rehabilitadas por sus inadecuadas condiciones, además de los costes coyunturales para las situaciones más apremiantes, entre los que están los generadas por los realojos de los desahucios y por las actuaciones urbanísticas.

Este déficit de una provisión de viviendas, que haría frente a las necesidades de unos hogares incapaces de afrontar los alquileres del mercado, se expresa en la escasa atribución económica en los presupuestos de los planes de vivienda estatales, lo que se repite en el conjunto de comunidades autónomas y municipios, con casos extremos como el del Ayuntamiento de Madrid que vendió a fondos de inversión internacionales 1860 viviendas sociales, una parte sustancial de su patrimonio, por 126,5 millones de euros, a lo que se añadió la venta de

\footnotetext{
7 Según los datos de 2008 del CECODHAS, recogidos en el informe sobre "la Vivienda Social en la Unión Europea", en los 27 miembros la U.E. habría una media del $9 \%$ de viviendas
}

2935 viviendas por la Comunidad de Madrid. Una acción que ya antes habían protagonizado otros ayuntamientos europeos como fue el caso de algunos de Alemania entre los que se contaban las 6.000 viviendas vendidas a fondos de inversión por la ciudad Berlín, en los primeros años del siglo actual y que recientemente se ha visto obligada a recomprarlas, pero por más del doble del valor de su venta.

El modelo de escasa inversión pública en vivienda que se orientaba a desarrollar el acceso en propiedad que se ha sostenido durante más de medio siglo con la concepción para un gran número de hogares de que se trataba de una inversión a largo plazo y un seguro de cara a su futuro (MUÑOZ \& SANTOS 2012), estuvo acompañado por la existencia de un parque mínimo desmercantilizado de viviendas sociales cuyas dimensiones experimentaron pocos cambios. La vigencia de este modelo se ha revelado incapaz de responder a las necesidades de ese fragmento de los hogares que no puede acceder al mercado en ningún tipo de régimen y que se ha visto obligado a alquilar una sola habitación, o a residir en una vivienda en condiciones inadecuadas La realidad ha sido que a pesar del descenso reciente de la inversión en la ayuda a los hogares para la adquisición de viviendas que constituía hasta hace poco la mayor parte de la inversión pública en vivienda, no se ha acometido una alternativa efectiva como sería la de un desarrollo del parque de viviendas sociales en alquiler.

Para la comprensión de esta situación hay que remontarse a más de medio siglo hacia atrás y considerar la utilización, con frecuencia contradictoria, de los principales instrumentos empleados en las políticas de vivienda y cuya combinación ha ido cambiando con el tiempo. Estos instrumentos podían agruparse en 6 tipos distribuidos entre los indirectos: financieros, fiscales, de reglamentación jurídica y los directos: producción de viviendas, de suelo urbanizado, y subvenciones.

La combinación de esas medidas tiene una composición diferenciada en cada uno de los periodos de las políticas de vivienda española a lo largo de algo más de medio siglo que transcurre desde mediados de los sesenta, comienzo del gran impulso manifiesto a la adquisición de las viviendas en propiedad para todas las categorias sociales, hasta la actualidad. El análisis detallado de estas intervenciones a través de

sociales en alquiler, lo que contrasta con el 1,5\% existente en España. 
un periodo tan extenso supera las posibilidades de este artículo, pero al menos podemos establecer sus líneas principales más recientes, para dar cuenta del declive de la mayor parte de ellos.

\subsection{Los planes de vivienda}

Se puede decir que el primer gran plan de vivienda es el de 1961 en el que se marcaba la existencia de un déficit de un millón de viviendas para todo el país que habría que compensar en los 16 años de vigencia del plan. Posteriormente los planes de vivienda quedaron incluidos dentro de los sucesivos planes de desarrollo económico y social que marcaban de forma bastante genérica las previsiones de edificación. Es a partir del año 1981 cuando los planes nacionales de vivienda adquieren una continuidad trienal, en la que se conjugan una serie de medidas que suponían la combinación de instrumentos de intervención directos e indirectos cuya composición ha ido variando en el tiempo, sobre todo en relación con las condiciones financieras y con las necesidades de alojamiento de la creciente población (GIACOMINI, 2014). En esos planes se detallaba la cuantía de la inversión en ayudas a la producción de definidos tipos de viviendas y de las ayudas para el acceso en propiedad de diverso tipo, habiéndoseles añadido desde los años noventa, las medidas de rehabilitación de un parque que envejece, la mitad de cuyas viviendas es anterior a 1970 (Censo 2011) y que necesita una continua adaptación ante su deterioro y las nuevas necesidades actuales de los hogares.

Se pueden establecer tres debilidades generalizables en la mayor parte de estos planes. La primera de ellas es la continuidad en la aplicación de algunas de las medidas que solo se abandonan con bastante retraso, incluso tras haberse constatado su poca o nula eficacia para resolver los problemas de acceso a la vivienda de los hogares menos favorecidos, como es el caso del fomento del acceso en propiedad, especialmente a través de la figura de las Viviendas de Protección Oficial. La segunda es la utilización de las medidas de actuación sobre la vivienda para fines que tienen muy poco que ver con este objetivo de facilitar el acceso a la vivienda, siendo justificadas por fomentar el empleo, para modular o atenuar las cargas fiscales de los hogares de rentas medias y altas o simplemente por rebajar las tensiones sociales de características diversas, como el acceso en propiedad de las viviendas públicas. La tercera es la tendencia a llevar a cabo políticas de dinero antes que políticas de prestación de servicios por las dificultades de la gestión o del control de esos servicios públicos, concretados en un parque de viviendas sociales, lo que también supone una tendencia hacia la privatización.

El saldo de esos planes que escenifican la orientación de la política de vivienda, en los 40 años continuados de su existencia, es el de su ineficacia en dar prioridad al desarrollo de medidas centradas en alojar a los hogares más vulnerables, excluidos del mercado. La medida del interés político de esos planes, nos la puede dar las dimensiones de la inversión que se les dedica, en la que se percibe un descenso notable, a lo largo de los últimos años. Dicho descenso se da en primer lugar por la justificada supresión de la desgravación fiscal que constituía su partida principal, sin que dicha supresión canalice el incremento de recaudación consiguiente hacia una intervención directa. Pero también, en la evolución reciente de la intervención directa tras la crisis financiera, de forma que, hasta el plan de 2019, las cantidades invertidas apenas llegaban para garantizar los compromisos adquiridos en los planes precedentes. Es decir que más allá de la supresión de la desgravación en 2012, el recorte de la inversión estatal directa en vivienda supera al de cualquiera de los sectores de inversión social, al quedar reducida a menos de la tercera parte de la que hubo en los últimos años de la década precedente (FIG. 8).

\subsection{La multiplicidad de objetivos que condicionan las políticas de vivienda}

La continuidad de las medidas más allá de su disfunción como ha sido el caso de las desgravaciones fiscales por inversión en vivienda

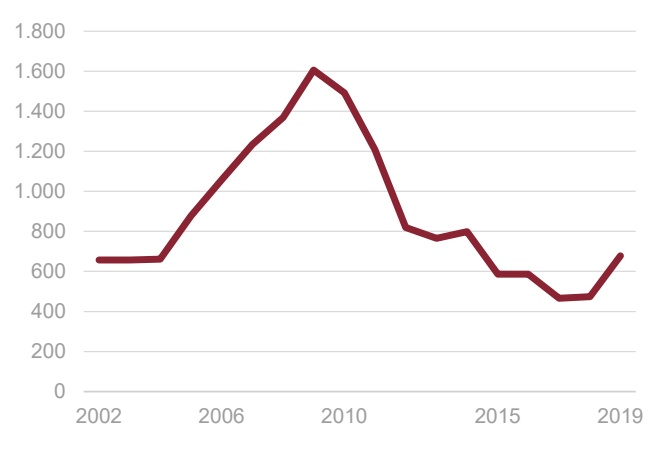

FIG. 8/ Evolución anual de los presupuestos de inversión directa en vivienda (miles de euros).

Fuente: MinISTERIO de HACIENDA EstadísticAs. Presupuestos Generales del Estado Consolidados. 
hasta 2012, exigida por las autoridades europeas, o la prolongación hasta nuestros días de la figura de las VPO en propiedad, hay que atribuirla a factores políticos ajenos a su pérdida de efectividad y dan idea de la escasa flexibilidad de las medidas en este sector.

Hay que tener en cuenta la influencia en esa continuidad del peso de la actividad de la construcción en la formación del Producto Interior Bruto que ha oscilado en los últimos años entre el $6 \%$ y el $12 \%$, con un empleo extenso de mano de obra, y con un elevado consumo de capital, que la convirtieron en un instrumento anticíclico en situaciones de crisis y de elevado desempleo, sobre todo en los años sesenta y setenta. Se trata de las medidas que se han denominado "ayudas a la piedra", en la que el objetivo era impulsar la construcción, frente a las ayudas a la persona e incentivos a las empresas que han ido sustituyendo a aquellas medidas anti cíclicas.

El análisis de las medidas de intervención que presentan los planes de vivienda nos lleva a establecer 6 de ellas más significativas cuya evolución refrenda el declive generalizado del modelo residencial.

\section{El agotamiento de las medidas}

\subsection{Una sociedad de propietarios no de proletarios}

Frente a lo que se ha dicho en algunas ocasiones, la elevada propiedad de la vivienda en España no es consecuencia de una preferencia cultural innata en los españoles. A mediados de los años cincuenta la proporción de propietarios era similar a la de los inquilinos, habiéndose polarizado la tenencia en propiedad como consecuencia de las políticas de vivienda que se han ido sucediendo, tanto las indirectas que penalizaban el alquiler, como, especialmente las que se llevan a cabo desde que, a mitad de los sesenta, el ministro de vivienda José Arrese proclamara que quería hacer un país de propietarios y no de proletarios. Esta intención hay que interpretarla como un intento de elevar artificialmente de categoría a los trabajadores, a una situación de pequeños burgueses propietarios que no desearían situaciones conflictivas que alteraran el valor de su propiedad, fruto de un ahorro, de forma que completaran la actitud de la escasa clase media existente para dar una mayor estabilidad al Régimen franquista. A esos motivos se añadía la dificultad de gestionar esos parques de vivienda social desde un organismo público central.

Las decisiones de impulsar la vivienda en propiedad llevaron por una parte a mantener el marco jurídico de los alquileres, con ciertas variaciones, que desaconsejaban las inversiones privadas en este tipo de viviendas, a la vez que se ponían en marcha programas de "accesión diferida a la propiedad" con una oferta a un coste muy favorable, para una buena parte de las viviendas sociales de titularidad pública que pasaron a ser propiedad de sus residentes, mermando sus existencias.

Para el resto de las viviendas libres en alquiler, la reducción de su proporción fue lenta porque los contratos que se hacían eran indefinidos e incluso transmisibles a los familiares directos, de forma que había que esperar a que el inquilino se cambiara de vivienda para poder actualizar las condiciones de alquiler.

La propiedad de sus viviendas, derivado de la continuidad de la aplicación de las medidas de política de vivienda, se percibía por los hogares como un alivio ante la inseguridad de las pensiones y la demanda constante de un aval para cualquier adquisición de bienes a plazo. Aunque la imagen de una inversión estable que producía su propiedad contrastaba con los ciclos repetitivos de subidas y bajadas de su valor que se fueron dando en las sucesivas crisis. Ha sido necesario experimentar variaciones de precios negativas o por debajo del IPC anual, con la última crisis económica, para darse cuenta de forma más clara de esa volatilidad de los valores inmobiliarios.

Desde comienzos de los años noventa ha habido repetidas manifestaciones de los gobiernos sucesivos sobre la necesidad de impulsar la vivienda en alquiler, pero no ha sido hasta la última década en la que una serie de medidas combinadas incide realmente en un aumento de esa forma de acceso, principalmente en las grandes ciudades. El punto de inflexión se manifiesta sobre todo en la ley de arrendamientos y el Plan de vivienda de 2013, junto con la supresión de las desgravaciones por la adquisición de la primera vivienda de 2012. Estas actuaciones suponen recortar los beneficios a la compra de viviendas a la vez que se favorece la inversión privada en alquileres, incrementando la seguridad de los arrendadores a cambio de provocar una mayor inseguridad de los inquilinos que pasaron por la reducción del tiempo de vigencia de los contratos de alquiler, y de su renovación. Esta ley venía acompañada del establecimiento de los juicios exprés que suponían la posibilidad de desahuciar a los inquilinos por impago de 
sus alquileres en un periodo breve. Con estas medidas se aceleró un proceso ya existente de crecimiento de los alquileres, hasta su estabilización por la saturación de la oferta anteriormente referida.

En la situación actual se plantearía la disyuntiva entre seguir impulsando los alquileres o volver a promover la adquisición de vivienda como acceso prevalente. Pero todo hace pensar que se da una gran dificultad de un mayor desarrollo de los alquileres privados y que las condiciones económicas de los hogares de rentas bajas tendrían que cambiar mucho para volver mayoritariamente a la propiedad de sus viviendas. En esta disyuntiva habrá que pensar en el desarrollo de un parque de vivienda social en alquiler adecuado a las capacidades de los menos favorecidos, aunque sea una apuesta a un plazo largo que supera el de cualquier periodo electoral.

\subsection{Las alternativas de la financiación}

Mientras la inflación fue elevada, la devaluación monetaria ocultaba la variación real de los precios de las viviendas e impulsaba las hipotecas, cuyo valor efectivo medido en términos absolutos en el momento de la contratación no variaba de forma acorde con la inflación. Ello suponía una desvalorización constante del montante de la hipoteca que hubiera beneficiado a los hogares cuyos ingresos si se ajustaban en relación con el cambio del valor de la moneda, si no hubiera sido por sus elevados intereses. Así, en1990 los préstamos hipotecarios tenían un tiempo de reembolso de 10 años con un interés medio del $15,5 \%$, acorde con la inflación del momento. La situación ha ido cambiando a medida que se reducía la inflación y en relación con la seguridad que supuso la introducción del Euro en el año 2002 debido a una extensión progresiva del tiempo de reembolso y una reducción de los intereses, la mayor parte de los cuales eran variables y referidos al Euribor, lo que provocó en torno al cambio de siglo en un considerable un aumento de los hogares que podían acceder a ser propietarios de sus viviendas, influyendo en la formación denominada "burbuja inmobiliaria". En la actualidad la media de duración de estos préstamos es de 24 años y los intereses variables rondan el $2 \%$, siendo los fijos alrededor del 3\%. A pesar de lo cual disminuye el acceso en propiedad por la dificultad de su financiación.

Las bajas tasas de interés que se establecen en España tras la inclusión en el Eurogrupo, aminoraron mucho el efecto de las políticas de subvención de intereses de las que se beneficiaban las viviendas de protección oficial, para las que habían sido inicialmente, junto con la garantía del préstamo hipotecario, su principal atractivo. Pero esta medida todavía tiene recorrido, no tanto para el mercado libre cuanto, por su posible aplicación al mercado de vivienda social, especialmente para la promovida por el sector público y por entidades sin ánimo. Para estas viviendas, las medidas de subvención de parte o de la totalidad de los intereses, junto con una extensión del reembolso de los préstamos a un horizonte mayor, con los correspondientes avales públicos, podría facilitar la extensión de un parque de viviendas sociales sostenible, con alquileres adecuados a las necesidades de los hogares de rentas medias y bajas, siempre que hubiera voluntad de gestionarlos por parte de los gobiernos de las comunidades y de los ayuntamientos.

\subsection{La política hipotecaria como medida de la política de vivienda}

La ley del suelo de 1956 puso las bases para un desarrollo urbanístico que posibilitaba la extensión del parque de viviendas, especialmente en las ciudades, pero cuyo desarrollo tenía el problema de la financiación que trató de resolverse con tres medidas, la primera fue la constitución de un banco público hipotecario que concediera los créditos que necesitaban los adquirentes de las viviendas protegidas, ya que las entidades financieras solo se interesaron por estos préstamos años más tarde. Para eso se creó un Banco Hipotecario público y se les impuso a las Cajas de Ahorros una cuota de sus recursos para esta financiación. Adicionalmente se concretaron las inversiones públicas en el abaratamiento de dichos créditos a las viviendas protegidas, a partir de una subvención de los intereses que habian de pagar los adquirentes. La ayuda financiera del Estado fue el principal fundamento para el desarrollo de las VPO.

Los promotores privados se acogían a esta figura de las VPO que, a partir de su comercialización rápida, incluso antes de su construcción, llegaron a suponer en algunos años de la década de los ochenta, más de la mitad de todas las viviendas construidas. Pero con el tiempo experimentaron un declive progresivo, con algunos altibajos, normalmente en relación con los precios establecidos como tope para ellas. Cuanto más bajos eran los precios establecidos menos interesaban a los promotores privados y viceversa. El problema es que, al bajar los tipos 
de interés de las hipotecas, estas viviendas empezaron a perder atractivo para los hogares.

La cuestión que se plantea actualmente es la de suprimir o transformar de nuevo esa figura para convertirla en un objeto efectivo de política social que vaya dirigido a facilitar el acceso en alquiler de los hogares que no pueden acceder a comprarse una vivienda, generalizando su destino de vivienda social en alquiler. Eso supone una nueva normativa para este tipo de viviendas que se podría aplicar a todos los nuevos proyectos de urbanización con operadores sin ánimo de lucro y privados.

\subsection{El agotamiento de las viviendas de protección oficial}

A pesar de las declaraciones de impulso al alquiler como las que se han venido dando desde comienzo de los años noventa (INAURRIETA, 2007), la realidad es que la figura de las VPO de acceso en propiedad continuó contribuyendo a extender la proporción de propietarios en el parque de viviendas español.

Las VPO han marcado toda la política española de vivienda durante más de medio siglo de su existencia, hasta nuestros días (TEJEDoR, 2010): en los que aún permanecen, aunque poco tienen que ver en la actualidad con sus condiciones iniciales ni con su volumen de construcción (FIG. 9). Esta figura estelar de la política de vivienda ha seguido manteniendo la misma denominación de su origen y continuado su concepción inicial como impulsora pública del acceso en propiedad, con ligeras variaciones como

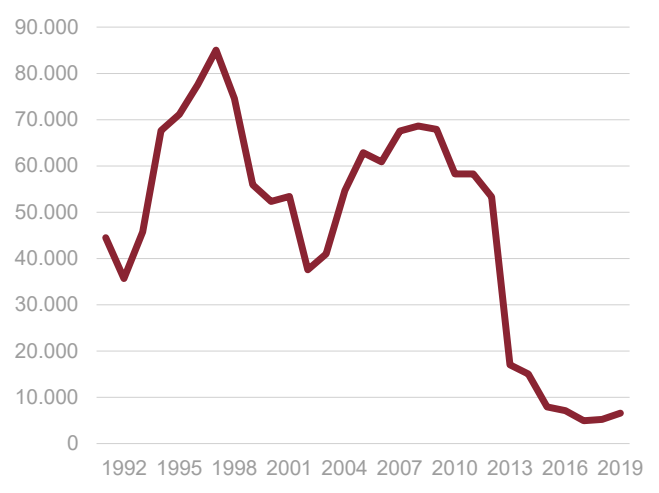

FIG. 9/ Evolución del total de VPO construidas en España (planes estatales y autonómicos, calificaciones definitivas) 1991-2019.

Fuente: MINISTERIO DE TRANSPORTES, MOVILIDAD Y AGENDA URBANA. las del alquiler con acceso a la propiedad o las de promoción pública para ser destinadas al alquiler de los hogares con menores rentas, aunque estas hayan tenido por objeto principal en los últimos años el realojo de los afectados por las remodelaciones de barrios y por las operaciones urbanísticas.

En la actualidad el principal beneficio que les queda a las nuevas promociones de VPO es el poder disponer de un suelo algo más barato ya que para garantizar su construcción, se reservan para ellas algunos solares en exclusiva en los planes y desarrollos urbanísticos desde finales de los años ochenta. Su imposición definitiva viene de la ley del Suelo de 2007 que establece una reserva para su edificación, en los planes de las ciudades mayores de 20000 habitantes. Hay que tener en cuenta que es el precio final de las viviendas lo que condiciona el precio de los solares para su edificación, de forma que, al estar establecido dicho precio tasado para estas viviendas por el gobierno, se condiciona el valor de los solares en los que solo ellas se pueden construir.

\section{5. ¿Es la mejor política de vivienda una política de suelo?}

La política que ha orientado las sucesivas leyes del suelo en España se ha concentrado en regular la intervención de los propietarios privados de suelo como los principales protagonistas de los desarrollos urbanísticos, planteando la urbanización como un negocio en el que el protagonismo de la administración se centraba en la redacción de los planes de urbanismo y en la regulación de las cargas y beneficios que debían tener los propietarios que transformaban el suelo en un espacio urbanizado. El punto de partida es que había que producir suelo susceptible de ser edificado como forma de abaratar los precios de la vivienda. Aunque los procesos muestran que al ser el suelo un bien único, ese planteamiento no es evidente.

Las leyes del suelo han condicionado una forma de crecimiento urbano que ha dado como resultado un tipo de ciudad, desde la ley expansiva de 1956, pasando por la regulación de las cesiones para equipamientos y la inclusión de la participación ciudadana de 1975. Pero a partir de la cesión de competencias de vivienda y urbanismo a las comunidades autónomas, nos encontramos con tantas leyes como comunidades, con características diferenciales, dejando a la Administración Central la función general de regular el derecho de propiedad y de establecer 
las medidas de valoración del suelo, de forma que la última ley, la de 2007 se limita a estas disposiciones básicas.

Actualmente, una parte importante de la responsabilidad de llevar adelante un parque de viviendas sociales es competencia de las comunidades autónomas. Son las leyes autonómicas de suelo y urbanismo las que regulan las cesiones y las reservas en la calificación de suelo en exclusividad para viviendas protegidas, pero corresponde a los ayuntamientos la gestión de esas cesiones y la aprobación de los proyectos. Esto ha llevado a diferencias notables en las políticas de vivienda entre comunidades e incluso entre ayuntamientos de una misma comunidad.

En este sentido los ayuntamientos y las comunidades tienen dos tareas inminentes en la provisión de suelo. La primera es la de fijar las cesiones de suelo para la construcción de viviendas sociales en alquiler a precios fuera de mercado, partiendo de la ley del suelo de 2007 que establece una cesión libre de cargas del aprovechamiento en términos de edificabilidad media ponderada total que puede oscilar entre el 5 y el $15 \%$ a los ayuntamientos e incluso llegar, como plantea el texto legal al $20 \%$. Pero además la ley fija por primera vez, con carácter general obligatorio para las leyes autonómicas un mínimo del $30 \%$ del aprovechamiento residencial para las VPO, recogiendo algo que ya estaba disperso en algunas leyes de suelo de las comunidades. La cuestión está en la utilización de las cesiones recibidas por ayuntamientos que podrían tener un destino obligatorio en la construcción de equipamientos y viviendas sociales en alquiler, dejando de lado la práctica de enajenarlas para engrosar las arcas municipales, práctica muy frecuente por gran parte de los ayuntamientos, derivada de la concepción del urbanismo como una fuente extraordinaria de ingresos municipales como expone ROGER (2008).

Adicionalmente, en la actualidad se plantea cada vez con más insistencia la necesidad de llevar a cabo procesos de rehabilitación de una parte creciente del parque residencial existente que debe ser abordado también por una normativa específica y constituirse en objeto de inversiones que provengan, en forma creciente, tanto de los presupuestos del Estado como de los presupuestos autonómicos. Hay que tener en cuenta que la ralentización del crecimiento de los hogares en los próximos años va a replantear el urbanismo expansivo, frente a la renovación de las viviendas existentes para adecuarlas a las necesidades de los hogares. En ese aspecto los ayuntamientos incrementan su responsabilidad en política de vivienda, ya que, por su mayor proximidad, deberán tener un peso más elevado.

Desde esta perspectiva se hace más difícil plantear una expansión de las viviendas sociales, ya que una parte de ellas debería venir de las viviendas rehabilitadas, lo que implica una gestión más complicada y un coste mucho más elevado.

\subsection{El fin de la desgravación fiscal de los adquirentes}

La desgravación fiscal por la inversión en la compra de una vivienda principal ha sido un instrumento prioritario en las políticas de vivienda desde 1979 hasta 2012, aunque la medida llegó a incluir en los años ochenta a las segundas residencias, como forma de impulsar la construcción.

Esta medida es uno de los recursos propios de las políticas de vivienda en muchos países, pero su generalización, independientemente de la renta de los adquirentes y su continuidad territorial y temporal, llegó a convertirla en España en un instrumento regresivo y contradictorio. Regresivo porque como ha demostrado SÁNCHEZ (2002), los que más se beneficiaban eran precisamente los hogares con mayores ingresos, a pesar de que a finales de los años noventa se limitó la cantidad máxima de desgravación al equivalente de $9000 €$ anuales. Pero además la generalización de su aplicación supuso la pérdida de su eficacia, ya que los vendedores, especialmente los de nuevas viviendas, incrementaban el precio contando con la mayor capacidad de endeudamiento de los hogares en relación con su desgravación, tal como sostiene RAYA (2019).

En realidad, sus efectos inducían un cierto aumento de la construcción de viviendas, aunque se aplicaba tanto a la adquisición de nuevas viviendas como a las de segunda mano. Si se hubiera asignado el montante global de esas deducciones a partir del siglo XXI, a la construcción de viviendas sociales en alquiler, podría haber más que doblado su volumen en ese periodo. Prueba de ello es que en la primera década del siglo la desgravación ascendió, según RAYA (2019) a un total de 53 mil millones de euros que significaban el $83 \%$ del total del gasto del Estado en vivienda. Aunque, incluso después de eliminada, la desgravación siguió todavía suponiendo un gasto superior a la inversión directa, ya que los beneficiarios anteriores a su eliminación se siguen desgravando por el 
tiempo de vigencia de sus hipotecas. La crisis financiera y el consiguiente retraimiento de la construcción que le sucedió no pudieron acabar con esa medida. Hay que tener en cuenta que, tras su supresión parcial en 2011, volvió otra vez a reponerse al año siguiente, hasta que fueron las exigencias de la Comunidad Europea las que impusieron su eliminación en correspondencia por las ayudas para el rescate financiero de la crisis económica de 2008.

\subsection{Las subvenciones}

Las medidas de ayuda directa al alquiler han sido otro de los instrumentos recientes, algo que está en consonancia con el carácter de la política de vivienda de los países del sur en los que, tal como se ha expresado anteriormente, predominan las políticas de ayuda económica directa o indirecta a los hogares, frente a la ayuda en servicios que supondría la existencia de un parque de vivienda social. Pero a diferencia de la continuidad experimentada por otras medidas como las del fomento de las VPO o de las desgravaciones fiscales, los beneficios directos a los hogares, como las ayudas del alquiler a los jóvenes han experimentado cambios considerables en los últimos años. Estas ayudas solo son eficaces si se concentran en un segmento determinado de esos hogares porque una generalización a todos los inquilinos actuaría de forma contradictoria al impulsar la elevación de los alquileres por cantidades similares a esas ayudas.

\section{Conclusiones}

A lo largo de estas páginas se ha tratado de argumentar la existencia de un cambio del modelo residencial español durante los últimos años. Dicho cambio tiene su mayor expresión en el incremento proporcional de la vivienda en alquiler que ha ido acompañado recientemente de un aumento de sus precios que afecta especialmente a los segmentos más vulnerables de los hogares de las grandes ciudades, compuesto por una parte de los jóvenes recién emancipados, los inmigrantes y en general los hogares de rentas bajas. Para ello se parte del sentido que tiene la vivienda y de sus funciones, que van mas allá que la de servir de cobijo a sus habitantes. Lo que muestra que la crisis de la vivienda tiene efectos considerables sobre las formas de vida de la sociedad española.

La argumentación del problema generado por este cambio de modelo pasa por comprender el crecimiento de la inadecuación entre las necesidades de disponer de una vivienda en régimen de alquiler, para los sectores mencionados, imposibilitados de comprar su vivienda y la escasa provisión de viviendas a precios asequibles. Esa inadecuación se originó por el agotamiento del parque de viviendas vacantes (secundarias y vacías) cuya puesta en el mercado de alquileres durante los años precedentes había respondido al incremento de la demanda de esta forma de tenencia. A esto se añadió la escasa disponibilidad de un parque de vivienda social por la falta de un presupuesto directo que incrementara su provisión para esos hogares.

La comprensión de esta situación ha llevado en primer lugar a analizar el proceso de los cambios recientes en la provisión y en las condiciones de acceso a la vivienda de los hogares. En segundo lugar, se ha examinado también la dinámica de los últimos años de la política de vivienda a partir del análisis de la evolución experimentada por sus principales medidas de intervención, mostrando el ocaso de gran parte de ellas, afectadas por la escasez de sus dotaciones, por su carácter continuista a pesar de sus resultados e injustas por la desigualdad en sus efectos regresivos sobre el patrimonio de los hogares. El recorte de la inversión directa en vivienda del Estado en la última década a un tercio de lo que fue en la década precedente contribuyó a acelerar estos desajustes.

Con esos precedentes no se atisba actualmente la posibilidad de incrementar sensiblemente el presupuesto que se exigiría para un cambio real del modelo para los próximos años, con el desarrollo de un parque de viviendas en alquiler que respondiera a las necesidades de los hogares con menos recursos. Esta dificultad se apoya también en la propia concepción del modelo para el que la provisión de alojamiento es en gran parte una cuestión familiar, siendo el mercado el que debe ser proveedor casi único que responda a las necesidades en transformación que tienen los hogares para su alojamiento.

En esta situación solo se puede plantear una nueva alternativa a partir de la revisión de la orientación de la intervención del Estado en todos sus niveles, tratando de conseguir, un notable incremento de las viviendas fuera de mercado, en régimen de alquiler que garantice su permanencia de titularidad pública y que sean asequibles al esfuerzo posible de los hogares más desfavorecidos. Esta alternativa habrá que simultanearla a la vez con subvenciones precisas y no generalizadas para resolver las situaciones más críticas, mientras no se alcanza un volumen adecuado del parque de vivienda 
social. Al mismo tiempo se hace necesario desarrollar una reflexión colectiva a partir de la consideración de los efectos que han tenido las medidas que se han aplicado y poder apuntar nuevas soluciones a un problema que se ha convertido en endémico en España.

\section{Bibliografía}

Abrahanson, P. \& Boje, T. \& Greve, B. (2005): Welfare and families in Europe. Londres Aldershot: Ashgate.

AlLEN, J. \& al., (2004): Housing and Welfare in Southern Europe. Londres. Blackwell.

Alves, P., \& URTASUn, A. (2019): Evolución reciente del mercado de la vivienda en España. Boletín Económico del Banco de España, Artículos Analíticos 2/2019.

ARBACI, S. (2019): Paradoxes of segregation: housing systems, welfare regimes and ethic residential change in Southern European countries. Londres. Blackwell.

CoRTÉs, L. (1995): La cuestión residencial. Bases para una sociología del habitar. Madrid: Editorial Fundamentos.

ECHAVES GARCIA, A. (2017): Emancipación residencial y sistema de provisión de vivienda: la heterogeneidad autonómica del modelo español. REIS Revista Española de Investigaciones Sociológicas: N. ${ }^{\circ} 159$, pp 51-71.

FLAQUER, L. (2004): La articulación entre familia y el Estado de bienestar en los países de la Europa del sur. Papers: Revista de Sociología, ‥ ${ }^{\circ} 73$ (2004), p. 27-58. https://ddd.uab.cat/record/35? In=ca

García AlmiRal, P. \& ARENDS Morales L.M. (2012): "Vivienda Social en la Unión Europea" Informe del Centre de Politica de Sól i Valoracions de la Universidad Politécnica de Barcelona.

(https://upcommons.upc.edu/bitstream/ handle/2117/18210/report1 lenimar vivienda+soc ial+en+la+uni\%d3n+europea.pdf;jsessionid=f77dc dd59319f7157fc9607b1750ecc9?sequence=1).

GaRcía PÉrez, E. \& JanOSCHKA, M. (2016): Derecho a la vivienda y crisis económica: la vivienda como problema en la actual crisis económica. Ciudad y Territorio Estudios territoriales. Vol. XLVIII (188).

García-MonTALVO, J. (2019): Retos del mercado del alquiler en España, Cuadernos de Información Económica, 269 (marzo/abril), pp. 11-21.

GiAcominI, A (2014): Evolución de las políticas de ayuda a la vivienda en España. Tesis de grado en Economía Curso 2013/14 Universidad del País Vasco. Facultad de Ciencias Económicas y Empresariales.

HAMMAD, M. (2006): Lire l'espace, comprende l'architecture. Limoges. Francia. Prese Universitaire de Limoges.

HeRnández Pedreño, M. (Coord.) (2013): Exclusión residencial. Universidad de Murcia. Servicio de Publicaciones.

INAURRIETA BERUETE, A. (2007): "Mercado de vivienda en alquiler en España: más vivienda social y más mercado profesional" Documento de trabajo 113/2007. https://www.fundacionalternativas.org/public/ storage/laboratorio documentos archivos/xmlimport-I1IEmQ.pdf 12/10/2020.

KeMENY, J. (1992): Housing and social theory. Londres. Routeledge.

LEAL, J. \& SoRANDo, D. (2016): "Economic Crisis, Social Change and Segregation Processes in Madrid", en TAMMARU, S. \& MARCIŃCZAK T. M. \& MUSTERD S. (eds.): Socio-Economic Segregation in European Capital Cities. Londres: Routledge, pp. 214-237.

LóPEZ RAMÓN, F. (coord.) (2010): Construyendo el derecho a la vivienda: Madrid Marcial Pons, Pgs.11-24.

LÓPEZ RodRíGuez, D. \& MATEA, M. R. (2019): Evolución reciente del mercado de alquiler en Boletín Económico del Banco de España, Artículos Analíticos n. ${ }^{\circ} 3 / 2019$,

MARTÍNEZ DEL OLMO, A. (2020): El sistema de vivienda del sur de Europa ¿continuidad o ruptura? RES Revista Española de Sociología, Vol 29, Numero 1, pgs 181-198.

Martínez Veiga, U. (1999): Pobreza, segregación y exclusión residencial: la vivienda de los inmigrantes extranjeros en España. Icaria. Barcelona.

MódENES, J. A. (2009): "La tenencia de la vivienda de la población rural española: Un (sub)sistema residencial en transformación". en: LóPEZ TRIGAL, L. \& Abellán, A. \& Godenau, D. [ed.]. Envejecimiento, despoblación y territorio. Universidad de León, p. 239-252

- \& LóPEZ-COLÁS, J. (2012): El sistema residencial: un esquema conceptual para entender la relación dinámica entre población y vivienda en España. Papers de Demografía, - Centre d'Estudis Demogràfics. Universidad Autónoma de Barcelona.

- (2014): Cambio demográfico reciente y vivienda en España: ¿hacia un nuevo sistema residencial? REIS Revista Española de Investigaciones

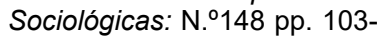

MUÑOZ FERNÁNDEZ, G. M.; \& SANTOS ROLDÁN, L. (2012): El patrimonio inmobiliario de los mayores como complemento al sistema de pensiones. Revista Internacional de Administración y Finanzas, Vol. 5, No. 1, pp. 17-32.

Muth, R. \& Goodman, A. (2013): The economics of housing market, Nueva York, Routeledge.

OBERTI, M. \& PRETECEILLE, E. (2016): Ségrégation urbaine Paris. La Découverte.

Pareja Eastway, M. \& Sánchez Martínez, M. T. (2012): La política de vivienda en España: lecciones aprendidas y retos de futuro. Revista Galega de Economía vol. $21 \mathrm{n} .{ }^{\circ} 2$.

- (2015): El sistema de vivienda en España y el papel de las políticas: ¿qué falta por resolver? Cuadernos Económicos del ICE, vol. 90, 2, semestre, p. 149-174.

Pezeu-Massabuau. J. (2013): La maison, espace social. Paris. PUF.

RAPPOPORT, A. (1972): Vivienda y Cultura. Barcelona, Editorial Gustavo Gili.

RAYA, J.M. (2019): Una aproximación al impacto económico de la recuperación de la deducción por la compra de la vivienda habitual en el IRPF. Cuadernos de trabajo Observatorio de Divulgación Financiera. 
https://www.iefweb.org/wp-content/uploads/ 2019/01/recuperacion deduccion compra vivienda irpf.pdf

Roch PEÑA, F. (2008): El problema del precio de la vivienda: morfología social y memoria colectiva. Revista Anthropos N..$^{\circ} 218$ Pgs 153-174.

RodRíGUEZ LóPEZ, J. (2019): Mercado de vivienda en expansión y desaceleración de la economía Ciudad y Territorio, Estudios Territoriales Vol. LI, N. ${ }^{\circ}$ 199, Págs. 403-414.

Roger, G. (2008): Urbanismo y financiación local. Papeles de Economía Española, 115, pp. 212-224.

SÁNCHEZ MARTínez, M. T. (2002): La política de vivienda en España. análisis de sus efectos redistributivos Universidad de Granada, Biblioteca de Económicas y Empresariales.
Segaud, M. (2008): Anthropologie de l'espace. París. Arman Colin.

TEJEDOR BIELSA, J. (2010): "Régimen jurídico general de la vivienda protegida," en LóPEZ RAMón, F. Construyendo el derecho a la vivienda. Madrid. Marcial Pons, 309-347.

TRILLA, C. (2001): La política de vivienda en una perspectiva europea comparada. Fundación La Caixa. Colección Estudios Sociales. Madrid.

VAQUER CABALlería, M. (2011): La eficacia y efectividad del derecho a la vivienda en España. Madrid. Editorial lustel.

Vinuesa ANGULO, J. \& Porras Alfaro, D. (2017): La dimensión territorial de la crisis de la vivienda y el despilfarro inmobiliario residencial Cuadernos de Relaciones Laborales, 35(1) 101-126. 